\title{
Influence of curing conditions on the mechanical properties and durability of cement mortars
}

\author{
J. M. Ortega ${ }^{1}$, V. Ferrandiz ${ }^{2}$, C. Antón ${ }^{3}$, M. A. Climent ${ }^{1}$ \\ \& I. Sánchez ${ }^{1}$ \\ ${ }^{1}$ Departament d'Enginyeria de la Construcció, \\ Obres Públiques i Infraestructura Urbana, Universitat d'Alacant, Spain \\ ${ }^{2}$ Departament de Construccions Arquitectòniques, Universitat d'Alacant, \\ Spain \\ ${ }^{3}$ Instituto de Ciencias de la Construcción Eduardo Torroja (CSIC), Spain
}

\begin{abstract}
Real structures are hardened in conditions different from the optimum laboratory conditions, where materials are usually tested. The different temperature, and especially the different relative humidity present in the environment, may cause a different microstructure and, as a consequence, different service properties. In this work mortars made with two different cement types are tested in laboratory conditions and at a lower relative humidity. These new environmental conditions cause a slower microstructural development and different durability and mechanical properties at early hardening ages.

Keywords: microstructure, environmental conditions, mechanical strength, durability.
\end{abstract}

\section{Introduction}

Durability and mechanical properties of cementitious materials are directly related to the microstructure of these materials [1]. In recent years the use of active additions in concrete has become quite popular. The particular case of ground granulated blast-furnace slag, and the effect on the properties of the cementitious materials is a topic of study [2]. They are known to reduce the diffusion coefficient of chlorides in concrete [3]. 
The different temperature [4], and especially the different relative humidity [5] present in the environment, may cause a different microstructure [6] and, as a consequence, different service properties, such as compressive strength [7] and the diffusion coefficient of chlorides [8] in concrete.

In this work mortars made with two different cement types, an ordinary Portland cement and ground granulated blast-furnace slag cement, were tested in laboratory conditions and at a lower relative humidity. The development of their microstructure, durability and mechanical properties were studied at early hardening ages, as a function of the relative humidity of the environment.

\section{Experimental setup}

\subsection{Sample preparation}

Mortar samples were prepared using an ordinary Portland cement (OPC), CEM I $42.5 \mathrm{R}$ (CEM I from now on), and a ground granulated blast-furnace slag (GGBS) cement (with a content of GGBS between $66-80 \%$ of total binder), CEM III/B 42.5 N/SR (CEM III from now on), according to the Spanish standard UNE EN 197-1. Two different water:cement ratios, 0.4 and 0.5, were employed. Fine aggregate was used according to the Spanish standard UNE EN 196-1. The aggregate to cement ratio was 3:1 for all the mortars.

Two kinds of specimens were prepared. Ones were cast in cylindrical moulds of $10 \mathrm{~cm}$ diameter and $15 \mathrm{~cm}$ height, while the rest were cast in prismatic moulds of dimensions $4 \mathrm{~cm} \times 4 \mathrm{~cm} \times 16 \mathrm{~cm}$ according to the standard UNE EN 197-1. Samples were kept in $95 \% \mathrm{RH}$ chamber and $20^{\circ} \mathrm{C}$ for 24 hours. After that time they were demoulded and cylindrical samples were cut into cylinders of $5 \mathrm{~cm}$ thick.

Curing conditions ( $\mathrm{RH}$ and temperature) were managed with glycerol solutions introduced in hermetically sealed containers. Solutions were prepared according to the German standard DIN 50008 part 1. Containers were introduced into a chamber with controlled temperature. There were two environmental conditions: curing condition A $\left(100 \% \mathrm{RH}\right.$ and $20^{\circ} \mathrm{C}$, optimum laboratory condition) and curing condition $\mathrm{B}\left(65 \% \mathrm{RH}\right.$ and $\left.20^{\circ} \mathrm{C}\right)$. The tests were performed at 7, 28 and 90 days of age.

\subsection{Mercury intrusion porosimetry}

In order to study the microstructure of mortar samples, a classical and wellknown technique, such as mercury intrusion porosimetry, was used. Samples were oven dried for 24 hours at $105^{\circ} \mathrm{C}$, even though this fact could change the contact angle between mercury and cement [9]. Two measurements were made on each sample. The porosimeter employed was an Autopore IV 9500 from Micromeritics. This porosimeter allows pore diameter determination in the range from $5 \mathrm{~nm}$ to $0.9 \mathrm{~mm}$.

It has to be considered, that as reported by Diamond [10, 11], only the dimensions of the pore superficial structure can be detected by MIP, and the irregularities in pore shape cannot be determined. However, information on the 
possible tortuosity of pore network can be obtained from the mercury retained in the sample after the end of the experiment. The analysis of the curve plotting the logarithmic differential intrusion volume vs. pore size, or applied pressure, shows the size where pores appear. The numerical analysis will be done calculating the volume of pores at different pore diameter intervals.

\subsection{Capillary absorption test}

The capillary absorption test was performed according to prUNE 83.982. This test is based in the Fargelund method to determine the capillarity of concrete. Samples of $10 \mathrm{~cm}$ diameter and $5 \mathrm{~cm}$ height were used. According to the Rilem recommendation TC 116-PCD [12], the circumferential surface was sealed using self-adhesive tape.

Samples were completely dried for 24 hours in an oven at $105^{\circ} \mathrm{C}$. The Rilem recommendation [12] suggests a saturation degree of $70 \%$ on samples. The election of complete drying was made in order to accelerate the test. Especially at early ages, the hardening of samples has not been completed, and the contact with water for a long period may cause changes in the microstructure, and these changes are not a result of the hardening environment. According to the prUNE 83.982, the samples were introduced in a container with a flat base. The container was filled with distilled water until $5 \pm 1 \mathrm{~mm}$ on the lateral surface and more than a $95 \%$ of the base of the sample was in contact with water. During the test, water level was kept constant and the container was hermetically closed. Samples were weighed at different times set in the standard. The test finished when the difference between two consecutive weights, with 24 hours difference, was lower than $0.1 \%$, in mass. The capillary suction coefficient and effective porosity were calculated according to the expressions:

$$
\begin{gathered}
\varepsilon_{e}=\frac{\mathrm{Q}_{\mathrm{n}}-\mathrm{Q}_{0}}{\mathrm{~A} \cdot \mathrm{h} \cdot \delta_{a}} \\
\mathrm{~K}=\frac{\delta_{a} \cdot \varepsilon_{\mathrm{e}}}{10 \cdot \sqrt{\mathrm{m}}} \text { with } \mathrm{m}=\frac{\mathrm{t}_{\mathrm{n}}}{\mathrm{h}^{2}}
\end{gathered}
$$

where $\varepsilon_{\mathrm{e}}$ is the effective porosity. $\mathrm{Q}_{\mathrm{n}}$ is the weight of the sample at the end of the test, g. $\mathrm{Q}_{0}$ is the weight of the sample before starting the test, $\mathrm{g}$. A is the surface of the sample in contact with water, $\mathrm{cm}^{2} . \mathrm{h}$ is the thickness of the sample, $\mathrm{cm} . \delta_{\mathrm{a}}$ is the density of water, $1 \mathrm{~g} / \mathrm{cm}^{3} . \mathrm{K}$ is the capillary suction coefficient, $\mathrm{kg} / \mathrm{m}^{2} \min ^{0,5} \mathrm{~m}$ is the resistance to water penetration by capillary suction, $\mathrm{min} / \mathrm{cm}^{2} \cdot \mathrm{t}_{\mathrm{n}}$ is the time necessary to reach the saturation, minutes.

For each cement type, curing condition and w:c ratio three different samples were tested.

\subsection{Forced migration test}

The forced migration test was performed according to NT Build 492. The result of the test is the non-steady-state chloride migration coefficient. The method required cylindrical samples with a diameter of $10 \mathrm{~cm}$ and a thickness of $5 \mathrm{~cm}$. Samples were saturated for 24 hours according to ASTM Standard C1202-97 
[13]. The specimens, introduced in rubber sleeves, were placed in the catholyte reservoir, filled with a $10 \% \mathrm{NaCl}$ solution. The reservoir above the specimen was filled with a $0.3 \mathrm{~N} \mathrm{NaOH}$ solution. The anode was immersed in the anodic solution.

An external electrical potential was applied across the specimens to force the chlorides to migrate into the specimen. The electrical potential and test duration was chosen according to the measured current applying an initial voltage of 30 $\mathrm{V}$. The value of the initial and final currents and temperatures were noted.

After the test, the specimen is axially split and sprayed with a silver nitrate solution $(0.1 \mathrm{~N})$. Chloride penetration depth was measured from the visible white silver chloride precipitate. The migration coefficient $\left(\mathrm{D}_{\mathrm{nssm}}\right)$ can be calculated from this average penetration depth $\left(\mathrm{x}_{\mathrm{d}}\right)$ according to the expression:

$$
\mathrm{D}_{\mathrm{nssm}}=\frac{0,0239 \cdot(273+\mathrm{T}) \cdot \mathrm{L}}{(\mathrm{U}-2) \cdot \mathrm{t}} \cdot\left(\mathrm{x}_{\mathrm{d}}-0,0238 \cdot \sqrt{\frac{(273+\mathrm{T}) \cdot \mathrm{L} \cdot \mathrm{x}_{\mathrm{d}}}{\mathrm{U}-2}}\right)
$$

where: $D_{\text {nssm }}$ is the non-steady-state migration coefficient, $x 10^{-12} \mathrm{~m}^{2} / \mathrm{s}, \mathrm{U}$ is the absolute value of the applied voltage, V. T is the average value of the initial and final temperatures in the anodic solution, ${ }^{\circ} \mathrm{C}$. $\mathrm{L}$ is the thickness of the specimen, $\mathrm{mm}$, and $\mathrm{t}$ is the test duration, hours.

For each cement type, curing condition and w:c ratio three different samples were tested.

\subsection{Mechanical strength test}

The strength was measured according to the Spanish standard UNE EN 196-1. Samples of dimensions $4 \mathrm{~cm} \times 4 \mathrm{~cm} \times 16 \mathrm{~cm}$ were tested. Compressive and flexural strength were studied. For each cement type, curing condition and w:c ratio three different samples were tested.

\section{Results and discussion}

\subsection{Mercury intrusion porosimetry results}

Total porosity, $\mathrm{Hg}$ retained and pore size distribution of the samples were studied. The results of total porosity are depicted in Figure 1(A). Samples with $\mathrm{w}: \mathrm{c}$ ratio 0.5 presented higher total porosity than with $\mathrm{w}: \mathrm{c}$ ratio 0.4 .

For curing conditions A, total porosity kept constant between 7 and 90 days in specimens prepared with CEM I. Only samples with w:c ratio of 0.4 have an important porosity decrease between 28 and 90 hardening days. Total porosity of samples of CEM III showed a high decrease between 7 and 28 days. This decrease only continued between 28 and 90 days for w:c ratio 0.5 specimens.

These results could mean that a higher $\mathrm{RH}$ accelerates the development of the hydration and pozzolanic reactions. With these reactions, new solids appear and total porosity decreases at early ages.

For curing conditions B, total porosity of CEM I samples and w:c ratio 0.5 kept constant until 28 days and decreased between 28 and 90 days. Total 
porosity in CEM III samples remained constant between 7 and 28 days, and decreased between 28 and 90 days. It can be thought that the lower RH slows down hydration and pozzolanic reactions, and the decrease of total porosity happens later.
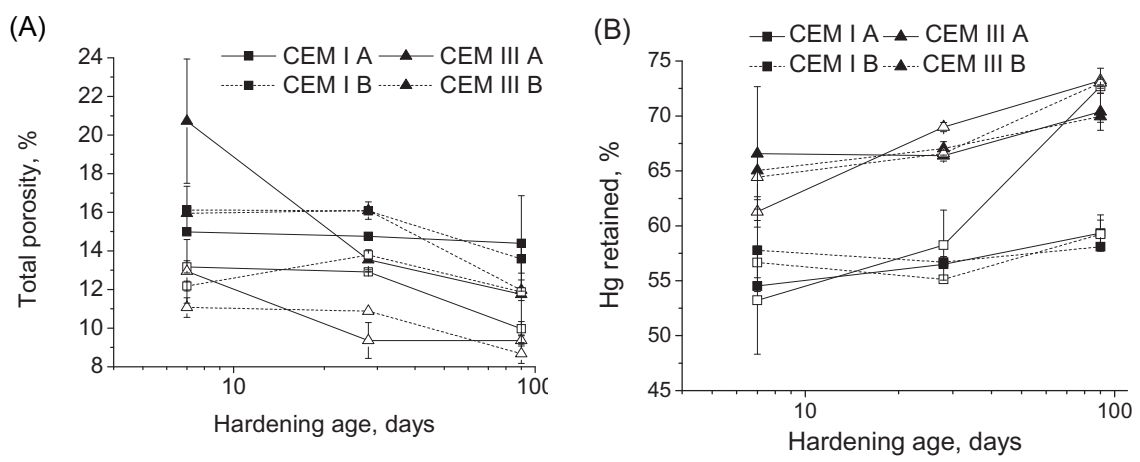

Figure 1: (A) Evolution with time of total porosity for both cement types and hardening conditions. (B) Results of mercury retained for specimens studied. Full symbols are for w:c ratio $=0.5$ while open symbols are for $\mathrm{w}: \mathrm{c}$ ratio $=0.4$.

The study of the mercury retained in the sample after the end of the experiment enables to obtain information of the possible tortuosity of pore network. The results of total porosity are depicted in Figure 1(B). The percentage of mercury retained increased in most of the samples studied. For samples cured under conditions A, this increase of mercury retained is higher than specimens under conditions B. These results could mean that a higher RH helps the hydration and pozzolanic reactions. Then new solids are quickly made and tortuosity of pore network increases.

The study of pore size distribution of samples was done considering the following diameter ranges: $<10 \mathrm{~nm}, 10-100 \mathrm{~nm}, 100 \mathrm{~nm}-1 \mu \mathrm{m}, 1-10 \mu \mathrm{m}, 10 \mu \mathrm{m}-$ $0.1 \mathrm{~mm}$ and $>0.1 \mathrm{~mm}$.

For all the samples studied, the majority ranges were $10-100 \mathrm{~nm}$ and $100 \mathrm{~nm}$ $1 \mu \mathrm{m}$. Values of the contributions to total porosity are shown in Figure 2(A) for samples prepared with CEM I. The intrusion volume decreased with age in these mortars. At 7 days of age, the intrusion volume is higher for CEM I samples under curing conditions B. However, this volume is similar for the majority of the specimens at 90 days of age, independently of curing conditions. The pores volume of majority ranges decreased with time. From these results, it can be said that the higher RH accelerates the hydration reactions of CEM I specimens, and then, the pores volume of majority ranges decreases mainly at early ages.

For specimens prepared with CEM III, the pore size distribution is shown in Figure 2(B). The intrusion volume decreased quickly for samples under curing conditions A. For curing conditions B, the intrusion volume decreased at 90 days of age. These results show that a high $\mathrm{RH}$ in the environment makes easier the 
development of pozzolanic and hydration reactions, and then, the intrusion volume decreases quickly. Nevertheless, if $\mathrm{RH}$ is lower, intrusion volume decreases later in the case of the cement type III that contains ground granulated blast-furnace slag cement.
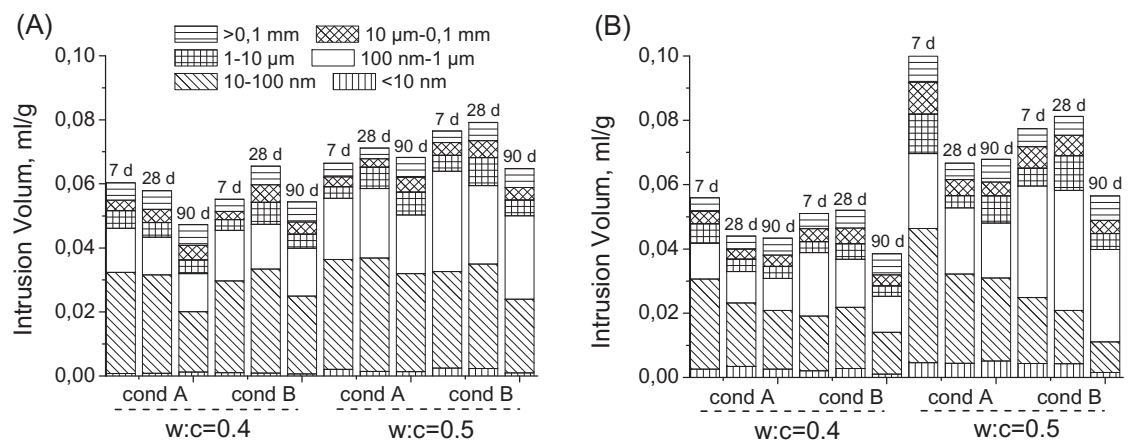

Figure 2: (A) Pore size distribution for CEM I specimens under curing conditions $\mathrm{A}$ and $\mathrm{B}$. (B) Pore size distribution for CEM III specimens under curing conditions $\mathrm{A}$ and $\mathrm{B}$.

\subsection{Capillary absorption test results}

The capillary suction coefficient $(\mathrm{K})$ and effective porosity of samples are obtained from the test. The results of capillary suction coefficient are shown in Figure 3(A). CEM I samples show a smaller coefficient $K$ than the CEM III samples. For the curing conditions A, samples prepared with CEM III and w:c ratio 0.4 had the highest coefficient $\mathrm{K}$ and it kept practically constant. Specimens with same type of cement and w:c ratio 0.5 presented lower coefficient $\mathrm{K}$ at the age of 7 days, but it increased with time. For both w:c ratios, the coefficient $\mathrm{K}$ for samples prepared with CEM III under curing conditions A was very similar at the age of 90 days.

The CEM I samples under curing conditions A had a small rise of coefficient $\mathrm{K}$ between 7 and 90 days of age. Specimens with w:c ratio 0.5 presented lower coefficient $\mathrm{K}$ than with $\mathrm{w}$ :c ratio 0.4 .

For the curing conditions B, samples with CEM III and w:c ratio 0.4 had higher coefficient $K$ than $w: c$ ratio 0.5 at the age of 7 and 28 days. The coefficient $\mathrm{K}$ at the age of 90 days presented a very important increase and had a very similar value for both $\mathrm{w}$ :c ratios. Specimens with CEM I and w:c ratio 0.5 had a smaller coefficient $K$ than $w$ :c ratio 0.4 at the age of 7 days. The coefficient $\mathrm{K}$ of $\mathrm{w}: \mathrm{c}$ ratio 0.5 samples decreased with the age and it increased for the samples with w:c ratio 0.4. At the age of 90 days the coefficient $\mathrm{K}$ was very similar for both w:c ratios.

The effective porosity of samples cured in conditions A was lower than the porosity of samples cured in conditions B. For both curing conditions, samples prepared with w:c ratio 0.5 had higher effective porosity than with w:c ratio 0.4 . 

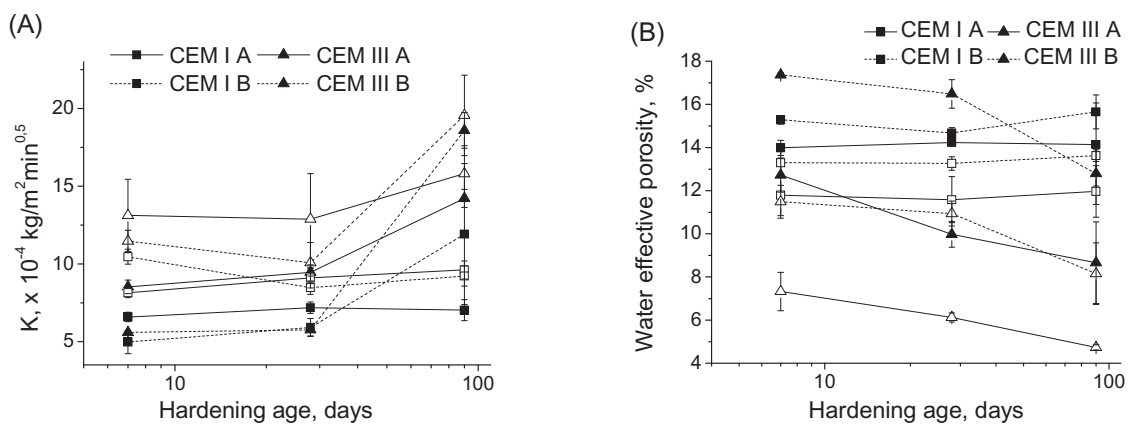

Figure 3: Results of capillary suction test. (A) Depicts the variation of the capillary suction coefficient with time for both cement types and hardening conditions. (B) Shows the water effective porosity also obtained from the test. Full symbols are for $\mathrm{w}: \mathrm{c}$ ratio $=0.5$ while white symbols are for $\mathrm{w}: \mathrm{c}$ ratio $=0.4$.

For curing conditions A, specimens with CEM III showed a lower effective porosity than with CEM I for the same w:c ratio.

As it can be seen in Figure 3(B) for each cement type, and w:c ratio the values of the water porosity are greater always under the curing conditions named B. This parameter has the physical meaning of the volume fraction accessible by water, and as a consequence by aggressive (i.e. chloride). This result proves that the laboratory conditions are optimal, and give a greater durability, from this point of view. This behaviour can be explained in terms of the higher $\mathrm{RH}$ present in the curing environment A. The unrestricted presence of water in the environment makes easier the development of the hydration and pozzolanic reactions. The products of these reactions are solid phases that cause a more compact structure of the materials.

When the $\mathrm{RH}$ is smaller than $100 \%$ (65\% condition $\mathrm{B})$ these reactions are slower, specially the pozzolanic reactions. This fact is reflected in the results of the effective porosity. As it can be seen, the influence of the relative humidity has a greater importance for CEM III. Samples hardened at 100\% RH show a decreasing tendency from the beginning of the study, while samples hardened at $65 \%$ RH show an important decrease of the effective porosity between 28 and 90 days. From these results it can be said that the lower relative humidity causes a slower development of the hydration and pozzolanic reactions, meaning that until 90 days a worse behaviour can be expected from the point of view of the aggressive ingress in concrete. The high decrease of the effective porosity from 28 to 90 days for the CEM III suggests a study at later ages, where the behaviour of cement with slag can be similar in both environments.

The behaviour of CEM III is always better than CEM I, and even in the hardening condition with less water, the difference in the effective porosity increases with time, which means a big improvement with time of the durability of mortars containing CEM III. 


\subsection{Forced migration results}

The results of the non-steady-state migration coefficient $\left(\mathrm{D}_{\mathrm{NTB}}\right)$ are depicted in Figure 4.

The migration coefficient has smaller values for samples prepared using CEM III than using CEM I. This result could be expected from the results obtained for the total, and water effective porosities. For mortar specimens with CEM I under curing condition A $(100 \% \mathrm{RH})$, the samples with w:c ratio 0.4 had the highest migration coefficient at 7 days age. The chloride migration coefficient obtained with these samples decreases with the hardening age, and at the age of 90 days their migration coefficient is the lower of all the CEM I samples.



Figure 4: Results of the non-steady-state migration coefficient $\left(\mathrm{D}_{\mathrm{NTB}}\right)$ for both types of cements studied. Full symbols are for w:c ratio $=0.5$ while white symbols are for $\mathrm{w}: \mathrm{c}$ ratio $=0.4$.

(A)

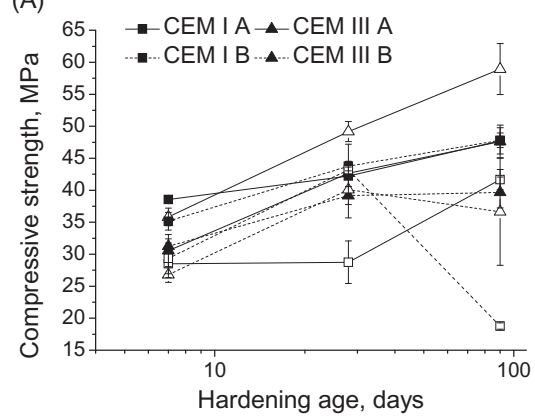

(B)

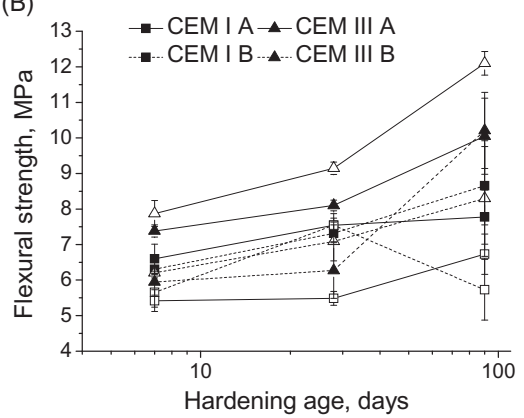

Figure 5: (A) Evolution of the compressive strength with the age of mortar samples. (B) Results of the flexural strength for specimens studied. Full symbols are for $\mathrm{w}: \mathrm{c}$ ratio $=0.5$ while white symbols are for $\mathrm{w}: \mathrm{c}$ ratio $=0.4$. 
For the curing conditions B $(65 \% \mathrm{RH})$, samples of OPC and w:c ratio 0.5 had higher $\mathrm{D}_{\mathrm{NTB}}$ than samples with $\mathrm{w}$ :c ratio 0.4 and both presented a similar decreasing tendency of $\mathrm{D}_{\mathrm{NTB}}$ between 7 and 28 days age. As should be expected from previous results, samples prepared with CEM III in curing conditions A had an important decrease of $\mathrm{D}_{\mathrm{NTB}}$ with special importance between 7 and 28 days. In curing conditions $\mathrm{B}$, the biggest decrease of the migration coefficient happened between 28 and 90 days. At the age of 90 days, $\mathrm{D}_{\mathrm{NTB}}$ was very similar for all the samples of CEM III.

Again, it is shown that a high $\mathrm{RH}$ in the environment makes easier the development of hydration and pozzolanic reactions, and then, the non-steadystate migration coefficient decreases quickly. Nevertheless, if RH is lower, the pozzolanic reactions develop slower and the non-steady-state migration coefficient decreases later, but also reaches good values for CEM III.

\subsection{Strength results}

Compressive and flexural strengths were studied. Compressive strength results are depicted in Figure 5(A). Flexural strength results are shown in Figure 5(B).

Both strengths increased in the majority of studied samples. For samples cured under conditions $\mathrm{A}$, this increase is higher than that obtained under conditions B. These results could mean that a higher $\mathrm{RH}$ accelerates the hydration and pozzolanic reactions. Then new solids are quickly formed and the gain of strength is faster in this case, in coincidence with all the results already discussed.

\section{Conclusions}

The main conclusions that can be obtained from the results previously discussed can be summarized as follows:

Relative humidity has an influence on materials properties. This influence is higher in cements containing ground granulated blast furnace slag (CEM III).

$\mathrm{Hg}$ retained is greater in CEM III mortar samples. This shows that the tortuosity of pore network increases due to the formation of new solids, by the hydration and also the pozzolanic reactions.

In general, CEM III samples show better properties of durability at 90 days of age.

High relative humidity improves slightly the durability properties of CEM I mortars. The presence of water favours hydration reactions of CEM I components.

The development of pozzolanic reactions and the formation of new solids, cause an important improvement of durability properties of CEM III mortars.

The improvement of the durability is delayed in environments with relative humidity lower than $100 \%$, but after 90 days hardening these properties have reasonable good values.

Compressive and flexural strength increased with the age in the majority of samples studied. 


\section{Acknowledgements}

This work has been financially supported by the Ministerio de Educación y Ciencia of Spain and Fondo Europeo de Desarrollo Regional (FEDER) through project BIA2006-05961. J.M Ortega is indebted to the abovementioned Spanish Ministry for a fellowship of the "Formación Personal Investigador (FPI)" programme (reference BES-2008-002650). Authors would like to thank Cementos Portland Valderribas, S.A. and Holcim España, S.A. for providing the cements studied in this work.

\section{References}

[1] I. Sánchez, M.P. López, M.A. Climent; Effect of Fly Ash on Chloride Transport through Concrete: Study by Impedance Spectroscopy; Proceedings of the 12th International Congress on the Chemistry of Cement; edited by J. J. Beaudoin, J.M. Makar and L. Raki; Durability and Degradation of Cement Systems: Corrosion and Chloride Transport; T4.044; published by the National Research Council of Canada; Montreal Canada; (2007). ISBN: 978-0-660-19695-4.

[2] J. Bijen. Benefits of slag and fly ash. Construction and Building Materials. 10, (1996) 309-314.

[3] M.D.A. Thomas, A. Scott, T. Bremner, A. Bilodeau, D. Day. Performance of slag concrete in marine environment. ACI Materials Journal. 105, (2008) 628-634.

[4] A.K. Schindler. Effect of temperature on hydration of cementitious materials. ACI Materials Journal. 101, (2004) 72-81.

[5] A.A. Ramezanianpour, V.M. Malhotra. Effect of curing on the compressive strength, resistance to chloride-ion penetration and porosity of concretes incorporating slag, fly ash or silica fume. Cement and Concrete Composites. 17, (1995) 125-133.

[6] J.I. Escalante-García, J.H. Sharp. The microstructure and mechanical properties of blended cements hydrated at various temperatures. Cement and Concrete Research. 31, (2001) 695-702.

[7] K. Ezziane, A. Bougara, A. Kadri, H. Khelafi, E. Kadri. Compressive strength of mortar containing natural pozzolan under various curing temperature. Cement and Concrete Composites. 29, (2007) 587-593.

[8] R.D. Hooton, M.P. Titherington. Chloride resistance of high-performance concretes subjected to accelerated curing. Cement and Concrete Research. 34, (2004) 1561-1567.

[9] C. Gallé. Effect of drying on cement-based materials pore structure as identified by mercury intrusion porosimetry. A comparative study between oven, vacuum and freeze-drying. Cement and Concrete Research. 31, (2001) 1467-1477.

[10] S. Diamond. Aspects of concrete porosity revisited. Cement and Concrete Research. 29, (1999) 1181-1188. 
[11] S. Diamond. Mercury porosimetry. An inappropriate method for the measurement of pore size distributions in cement-based materials. Cement and Concrete Research. 30, (2000) 1517-1525.

[12] Rilem recommendation TC 116-PCD: Permeability of concrete as a criterion of its durability. Materials and Structures. 32, (1999) 174-179.

[13] ASTM Standard C 1202-97: Standard test method for electrical indication of concrete's ability to resist chloride ion penetration. Annual book of ASTM Standard Section 4 Vol 04.02 (2000). 